\title{
Economic and Psychosocial Impact of Problem Gambling in South Korea
}

\author{
JongSerl Chun ${ }^{1 *}$, Sangmi Cho ${ }^{1}$, Ick-Joong Chung ${ }^{1}$, Seiwan Kim² \\ ${ }^{1}$ Graduate School of Social Welfare, Ewha Womans University, Seoul, South Korea; \\ ${ }^{2}$ Department of Economics, Ewha Womans University, Seoul, South Korea \\ *Corresponding author; email: jschun@ewha.ac.kr
}

\begin{abstract}
The study examined the harmful effects of casino gambling in Korean society from economic and psychosocial perspectives. Interviews with gambling addicts were conducted in order to gain insight into the impacts of pathological gambling. Using snowball sampling, 12 gambling addicts were recruited in Kohan, South Korea. Findings of the study suggest that gambling addicts suffer various harmful effects, including an increased susceptibility to financial and employment problems, such as debt and accumulated interest, bankruptcy, job loss, and decreased productivity. Participants in the study complained of physiological problems, including headaches, high blood pressure, arthritis, indigestion, a stomach disorder, and rapid weight loss. Common psychological problems reported included symptoms of high-level stress, depression, anxiety, insomnia, and suicidal ideation. For some interviewees who smoked and drank alcohol, consumption of these substances increased in response to their gambling. All participants reported disrupted relationships with their immediate family, relatives and friends. Moreover, they experienced stigma, discrimination, and feelings of alienation. With regard to criminal and legal problems, they were exposed to increased risk of litigation and violence. Clinical and political attention should be paid to the issue of gambling addiction in Korea, with a view to the prevention and treatment of gambling disorders. Management of gambling problems needs to consider economic and financial wellbeing, employment, physical and psychological health, interpersonal relationships, and the risk of criminal involvement and other legal issues.
\end{abstract}

Key words Economic and Psychosocial Impact $\cdot$ Problem Gambling

\section{Introduction}

Six different forms of gambling are legally licensed in South Korea: casinos, 
horse racing, cycle racing, boat racing, lotteries, and sports promotion lotteries. The Korean National Gaming Control Commission (2009) reported a total of 17 casinos (one for Koreans and 16 for foreigners only); seven racing tracks (three horse racing, three cycling, and one boat racing); 12 types of lottery including sports, welfare, charities, veterans health, housing, and tourism; and 16 separate sports promotion lotteries. The commission also estimated that the industry was worth 16.5 bn KRW (US\$16.5 bn) in 2009, a 3.3\% increase compared with 2008. Of particular note was the comparison with 2002 figures, when industry activity was estimated to have a value of 12.6 bn KRW (US\$12.6 bn). This indicated that the gambling industry had expanded by approximately $30.7 \%$ over this period, with an average annual growth of $3.9 \%$ between 2002 and 2009. Although growth was somewhat sluggish during 2004 and 2005 due to decreased lottery sales and widespread illegal gambling, the legal gambling market had clearly been growing rapidly over the period as a whole.

Using the Canadian Problem Gambling Index (CPGI; Ferris \& Wynne, 2001), the Korea Racing Authority (2009) conducted a survey to investigate the prevalence of pathological gambling in South Korea. The survey included 20,175 Korean adults, with $4.9 \%$ found to have moderate-risk gambling and $1.4 \%$ problem gambling. A recent investigation of gambling activity by the Korean National Gaming Control Commission (2010) had similar findings. The 2010 study showed that of the 1,797 participants, a total of $6.1 \%(n=110)$ were problematic gamblers (4.4\% with moderate-risk gambling and $1.7 \%$ problem gamblers). This indicates a serious problem: the extrapolation is that $2.3 \mathrm{mn}$ Korean adults are susceptible to gambling problems and $1.65 \mathrm{mn}$ are in need of intensive treatment. These figures are 2 to 3 times higher than those of other countries that have conducted surveys with the CPGI: 3.3\% for Canada; 2.4\% for Australia; and 1.9\% for England (Korean Problem Gambling Counseling Center, 2010).

Pathological gambling is defined by American Psychiatric Association (2000) as loss of control over gambling, a gambling preoccupation, withdrawal and tolerance, and a continuation of the behavior, despite adverse consequences. Addictive gambling has significant negative effects including on financial status, employment, criminal activity, on physical and psychological health and on interpersonal relationships. Moreover, it has a negative ripple effect in these areas beyond individuals to society at large (Abbott \& McKenna, 2005).

A brief literature review shows that problem gamblers often experience financial difficulties caused by bankruptcy and gambling debts, unemployment or threats of dismissal due to reduced efficiency and productivity. As a result of this financial 'ruin', some problem gamblers may find themselves sinking to the lowest economic and social stratum (Ko et al., 2006). Problem gamblers' financial problems affect the entire family, often creating substantial stress, and resulting in insufficient financial resources being available for their children's upbringing and education (Lee, 2003). Furthermore, on a societal level, it is estimated that gambling addiction is responsible for economic and social costs of 54 bn KRW (US\$54 bn) per year (Han et al., 2009). The adverse effects of excessive gambling also have a negative impact on the growth of local communities (Lee, 2002; Park, 2008).

Gambling addiction is detrimental to psychological and physiological health. Psychological issues that may arise as a result of gambling include raised levels of 
anxiety, increased anger, harmful pleasure seeking, and general loss of self-control (Jung et al., 2009; Lee, 2002). In addition, addictive gambling can contribute to the development of depression, drug or alcohol abuse, and suicidal intent (Hong, 2009; Lee, 2009; Lee, 2002; Lesieur \& Rosenthal, 1991; Pietrzak \& Petry, 2006). In one survey, $76 \%$ of gambling addicts complained of depression and $20 \%$ had tried to commit suicide (Lee, 2003); in another survey, $47 \%$ to $52 \%$ of the addicts reported drug or alcohol abuse (Lee, 2002). Other problems reported by gamblers include lethargy, anxiety, panic disorders, and other stress-related symptoms (Hong, 2009; Lesieur \& Rosenthal, 1991; Pietrzak \& Petry, 2006).

The impact of pathological gambling on the family is also often significant. According to Lee (2002), gamblers are in frequent conflict with family members at risk of disintegration. Addictive gambling disrupts intra-family communication, and is a major cause of spousal conflict and parent-child conflict. As the conflict worsens, the family often experiences the impact of the parents' separation and divorce. The 2009 Korea Racing Authority survey found that 53.5\% of pathological gamblers were divorced, a figure 3 times that of non-gamblers (Korea Racing Authority, 2009).

Additionally, gambling is related to various crimes such as fraud, embezzlement, forgery, tax evasion, and theft. These crimes can take place in the course of securing resources for gambling. The maintenance of a gambling habit may even lead to involvement with prostitution and human trafficking (Lee, 2003). Criminal activity associated with gambling is a significant concern and one that impacts on all members of Korean society.

In South Korea, few studies have been conducted to examine the economic and psychosocial impact of problem gambling. Using semi-structured interviews, the current study examined the effect of problem gambling on gamblers' finance and employment status, physical and psychological health, social relationships, and involvement in crimes and related legal issues. This study aimed to provide insights to assist in the development of appropriate prevention and treatment programs, specialist training, and government policy.

\section{Method}

Qualitative research methods were used involving interviews and subsequent thematic analysis of the interview data. One-to-one interviews were conducted to collect the interviewees' experiences of physical, psychological, financial, social and interpersonal problems caused by problem gambling.

\section{Participants}

Twelve participants were interviewed at a gambling rehabilitation center in Kohan where a Korean-exclusive casino is located. All participants lived near the casino, and were assessed as pathological gamblers meeting at least five DSMIV diagnostic criteria for a gambling disorder (American Psychiatric Association, 2000). Participants' socio-demographic information is summarized in the Table.

Six participants were men and six were women. Six were middle-aged, and six were aged over 55 years. Only one had not received any formal education. One had finished elementary school, three had graduated from middle school, six had 
completed a high school education, and one was a university graduate. Regarding marital status, seven were divorced, three were separated from their spouse, and one was widowed. Six were Buddhists, one was a Catholic, and the others had no religious affiliation. Ten of the 12 participants had children.

\section{Sampling strategy and procedure}

Snowball sampling method was used to recruit gambling addicts. Initially, six potential interviewees were referred by the gambling rehabilitation center. All six were contacted; however, only one attended an interview. Using this key informant as a source, 11 more participants with similar sample characteristics were recruited. Therefore, a total of 12 gamblers participated in the interviews. Of the 17 approached to participate, 12 gamblers were interviewed (a participation rate of $70.6 \%$ ). All interviews were conducted in the gambling rehabilitation center. None of the respondents was receiving treatment for gambling at the time of the interview.

At the beginning of the interview, the interviewer first explained the purpose and method of the planned interview. The participant was asked to formally consent to the interview and signed a written form of consent. Four professors, all of whom had extensive experience in qualitative research, took the role of interviewer. Using a semi-structured questionnaire, they conducted one-to-one interviews, each of them approximately an hour in length. The entire interview process was recorded and transcribed with the consent of the participant.

Table. Demographic data of survey participants

\begin{tabular}{lcclll}
\hline $\begin{array}{l}\text { Participant } \\
\text { No. }\end{array}$ & Sex & $\begin{array}{c}\text { Age } \\
\text { (years) }\end{array}$ & Education & Religion & Marital status \\
\hline 1 & M & 48 & High school & Nil & Divorced \\
\hline 2 & F & 53 & High school & Nil & Divorced \\
\hline 3 & M & 42 & Middle school & Catholic & Divorced \\
\hline 4 & F & 62 & Middle school & Nil & Separated \\
\hline 5 & M & 51 & High school & Buddhism & Not clear \\
\hline 6 & M & 58 & High school & Buddhism & Divorced \\
\hline 7 & F & 57 & No formal education & Buddhism & Separated \\
\hline 8 & M & 54 & High school & Nil & Divorced \\
\hline 9 & F & 59 & Middle school & Buddhism & Widowed \\
\hline 10 & F & 53 & Elementary school & Buddhism & Divorced \\
\hline 11 & M & 69 & University & Nil & Divorced \\
\hline 12 & F & 61 & High school & Buddhism & Separated \\
\hline
\end{tabular}




\section{Research questions}

Participants were asked to respond to our semi-structured questionnaire. Core research questions were as follows:

1. Please describe any kind of financial problem you have had as a result of gambling;

2. Please describe any kind of employment problem you have had as a result of gambling;

3. Please describe any kind of relationship problem you have had as a result of gambling;

4. Please describe any kind of physical or psychological problem you have had as a result of gambling;

5. Please describe any kind of crime-related or legal problem you have had as a result of gambling.

\section{Data analysis}

Thematic analysis was conducted following the methodologies outlined by Van Maanen (1988) and Ely et al. (1991). Based on the interview transcripts, responses from each participant were reviewed and then analyzed by using thematic categories which were subsequently endorsed by the researchers.

\section{Results}

The study found that the gamblers interviewed had social and psychological problems, mainly in the areas of finance, employment, physical and mental health, interpersonal relations, and relating to crime and legal status.

\section{Financial difficulties}

"Having borrowed money from loan sharks, accumulated interest is now greater than the principal."

All the participants experienced financial problems. Participants stated that they suffered economic losses ranging from $200 \mathrm{mn}$ KRW to $4.8 \mathrm{bn}$ KRW. All subjects reported having expended their financial resources in supporting their addiction, including selling or remortgaging of property (house or a business such as a restaurant or a shop). Nine of the 12 admitted to having used personal loans and credit cards to get money to gamble. As loan interests snowballed, they fell into greater debt. All participants reported having borrowed money from relatives, friends, or from private money-lenders, rather than standard financial institutions.

\section{Employment problems}

"I was not motivated to work because I was so tired after gambling. I was fired from my job."

Participants also reported job losses and decreased productivity since starting gambling. The majority had either left their jobs $(5 / 12)$ or closed their own (small) businesses (3/12) due to their gambling addiction. All male participants (6/12) reported that they could not work effectively because of fatigue after long hours of gambling and that they were preoccupied with thoughts of gambling. Several 
of them had been working part-time in restaurants or construction sites near the casino, living 'hand-to-mouth'. Four participants were prohibited from entering the casino because they were caught illegally selling and buying rights to play in particular machines that are deemed to be 'lucky'. Of the six women interviewed, four had been housewives and two were owners of small shops. Four of the six currently make a living by working at restaurants, with the average daily pay of KRW 50,000. However, most of the women (5/6) reported a lack of work interest or effort.

\section{Physical and psychological health}

"When I concentrate on gambling, I can't eat anything. When I lose money, I lose my appetite too and I don't have money to buy something to eat...so, I lost weight, $10 \mathrm{~kg}-$ from $65 \mathrm{~kg}$ to $55 \mathrm{~kg}$."

Although all participants complained of physical and psychological ailments, few received appropriate treatment. Their physical complaints included headaches, high blood pressure, arthritis, diabetes, a stomach disorder, and heartburn. Some participants $(6 / 12)$ reported significant fluctuations in body weight and gastrointestinal disturbances caused by irregular eating habits. Many participants $(9 / 12)$ responded that, while they were gambling, they were unaware of such symptoms or fatigue.

The commonly reported symptoms included high levels of stress, depression, anxiety, insomnia, and lethargy. Several gamblers experienced auditory hallucinations and relied on ataractic drugs for coping with the symptom. One gambler noted: "When I was obsessed with the slot machines, I had auditory hallucinations. The ringing sound of a jackpot was always present in my ears."

Half of the participants indicated that they drank and smoked more as a result of their gambling than previously. Although many said that they did not drink while gambling for fear of impairing their judgment, they reported indulging in alcohol to celebrate or commiserate about their winnings or losses.

Among the participants in the study, no one had attempted suicide, but almost all $(11 / 12)$ said that they had at some point felt strongly tempted to do so. Some participants $(4 / 12)$ reported that they had been distressed about knowing of other gamblers committing suicide. "I always think about suicide, but have never actually attempted it. When I heard that a young gambler had committed suicide, I felt sympathetic towards him."

\section{Disrupted interpersonal relations}

"I have not contacted anyone in my family since my divorce. I don't think they would want to see me anymore, and this makes me feel very lonely and depressed."

Many participants reported disrupted relationships with their family members, relatives and friends. With the exception of one gambler who began gambling after his wife's death, most of the participants were either divorced (7/12) or separated from their spouses (3/12). The subjects who were separated said that they were afraid to attempt to reunite with their families. One man sent living expenses to his family for his daughter's college tuition. However, for most family relationships were almost non-existent. 
Participants commented that gamblers tried to build a network among themselves to look for jobs or housing. However, they tended to not trust each other owing to prior complications in dealing with money. Some gamblers (3/12) avoided this kind of relationship-building altogether as they were of the view that genuine relationships between gamblers did not exist.

All of the participants reported experiencing discrimination, alienation, and feelings of loneliness, with some (3/12) even expressing antagonistic feelings towards society. Many participants reported gradually losing contact with their friends (10/12) as they became more involved in gambling because they borrowed money from them which they failed to repay $(8 / 12)$ or because they were fully occupied with gambling activities. Some participants voiced regret that they could not go to their parents' funerals.

All of the participants felt that they were looked down upon or discriminated against by the casino employees and even by other players. Some thought that only wealthy gamblers were respected $(4 / 12)$. Three gamblers remarked that they did not like the people they encountered at the casino, and preferred to remain alone. The casino was not considered to be the right place for developing genuine relationships by many $(10 / 12)$. A number commented that conflicts could emerge when gamblers fought for a 'good spot' or a 'lucky seat' $(7 / 12)$ or when they were asked for money to gamble $(6 / 12)$.

\section{Criminal and legal problems}

"I was involved in a lawsuit two years ago. The money lender sued me for defaulting. After the court hearing, I lost contact with the court staff, so I don't know how much money I owe, or even if I have to pay."

Although no interviewees reported any serious involvement in crime, many experienced small gambling-related legal disputes or litigation (9/12). Most of the participants $(9 / 12)$ said that they could not declare themselves insolvent or receive legal counseling because of the cost. Two participants said that counseling would not be practical because there were no counselors who specialized in gambling addiction. One of the subjects reported a money-related dispute with a friend.

In addition, some participants $(3 / 12)$ had been involved in violent altercations with other gamblers due to money or competition over preferred seats in the casino. One reported that he was involved in several fights at times when he was drunk after losing money at the casino.

\section{Discussion}

This study replicates and confirms previous research findings on the deleterious effects of pathological gambling on gamblers' finance (e.g., Han et al., 2009; Ko et al., 2006; Lee, 2002; Park, 2008), employment (e.g., Lee, 2002; Park, 2008), physical and psychological health (e.g., Hong, 2009; Lee, 2009; Lee, 2002; Lesieur \& Rosenthal, 1991; Pietrzak \& Petry, 2006), family and social relationships (e.g., Lee, 2002; Korea Racing Authority, 2009), and with respect to criminal activity and legal status (e.g., Lee, 2003).

The study results have potential implications for intervention, public education, and health policy. For those with gambling debts or legal problems 
relating to their gambling, debt counseling and legal assistance would appear to be of benefit. Some gamblers may also need help in finding work or with other employment-related issues. Our findings suggest a need to introduce a support system, such as the Employee Assistance Program (EAP), to provide preventive and intervention services for workers having trouble with gambling. More workers in developed nations are requesting services such as EAP to assist them with a range of diverse problems and such services can increase awareness of gamblingrelated information and provide necessary resources (Park et al., 2007).

The pathological gamblers interviewed in this study reported physical ailments and psychological issues, with cost a major treatment barrier. Gambling treatment centers need to be able to diagnose and treat pathological gamblers' problems or refer them as appropriate to other institutions. The prominence of suicidal thoughts among gamblers in this study, along with reported attempted suicides among their gambling contacts, suggests a need for crisis intervention and support services. In addition, gambling counselors might incorporate psychosocial intervention strategies to promote gamblers' psychological and social functioning, with a view to helping rebuild family relationships and social ties, and enhancing overall psychological health. Family doctors and psychiatrists can also play a vital role in the management of gamblers' physical and mental health problems. Ideally, intervention for gambling problems should include a team who are able to address educational, emotional, family relationship-building, and employment and financial needs, and to offer rehabilitation programs. In short, it would seem that interdisciplinary intervention would be beneficial to provide for holistic treatment and recovery.

It is important to recognize that the negative impacts of gambling are not limited to problems for the individual gamblers, but also involve significant repercussions for families. Therefore, measures should be taken to provide assistance to families and to provide professional expertise to facilitate relationships between gamblers and their families. As part of this, initiatives such as self-help groups for families need to be established. Of note, gamblers' spouses have been shown to have high levels of physical, emotional, and mental health problems (Leung et al., 2010). Specialists in the management of gambling addiction from a variety of professional fields are needed therefore, in order to meet the overall needs of the families of those with gambling problems.

It would also seem of value to improve public health information about the negative impacts of problem gambling. Effective preventive problems and culturally sensitive intervention strategies need to be developed. Systematic evaluation of the effectiveness of both remedial and preventive programs is needed in South Korea.

A number of pathological gamblers interviewed did not ask for legal counseling because they were unable to afford it. Even if they received counseling, they felt it was not practically helpful, because there were no specialists in the pertinent field. Therefore, the authors would recommend on the basis of this study that free legal counseling services for gamblers be readily available. In addition, those providing this service should have appropriate prior knowledge concerning gambling.

Since gambling research is a relatively new area in South Korea, this study 
serves to provide some evidence-based information to inform intervention and policy improvement. This qualitative study recruited a small sample of Koreans with problem casino gambling. Generalization of study findings to gamblers addicted to other types of gambling should therefore be made with care. However, the study does serve to deepen our understanding of the harmful impacts of problem casino gambling. Future qualitative or quantitative research should recruit larger samples of subjects. Both studies involving gamblers and investigating the impact on family members are needed.

This study examined negative consequences of problem gambling. Future research may further investigate these negative 'costs' as well as possible benefits of gambling activity for the individual or the community.

\section{Acknowledgments}

This study was funded by the Korean National Gambling Control Commission.

\section{References}

Abbott, M. W., \& McKenna, B. G. (2005). Gambling and problem gambling among recently sentenced women in New Zealand prisons. Journal of Gambling Studies, 21, 559-581.

American Psychiatric Association. (2000). Diagnostic and statistical manual of mental disorders (4th ed, text revised). Washington, DC: American Psychiatric Association.

Ely, M., Anzul, M., Friedman, T., Garner, D., \& Steinmetz, A. C. (1991). Doing qualitative research: circles within circles. New York: Falmer.

Ferris, J., \& Wynne, H. (2001). The Canadian Problem Gambling Index: final report. Toronto, ON: Canadian Centre on Substance Abuse.

Han, S. Y., Lee, H. P., Hur, T. K., \& Jang, H. (2009). The actual condition, participation rate of gambling and prevalence of pathological gambling in South-Korea - Based on gambling type. Korean Psychological Association: Health, 14, 255-276.

Hong, J. K. (2009). Psychoanalytic approach to the addition of gambling. Journal of Lacan $\mathcal{E}$ Contemporary Psychoanalysis, 11, 137-153.

Jung, S. Y., Son, D. S., Choi, Y. S., Shin, H. H., Kim, S. H., \& Choi, Y. S. (2009). A study on the development and effectiveness of social-psychological rehabilitation program for gamblers. Mental Health \& Social Work, 32, 285-320.

Ko, E. A., Ku, T. K., Kim, J. H., \& Chae, H. J. (2006). Study on economic approach and solution to gambling industry. Korean Journal of Alumni in Management, 37, 1-25.

Korea Racing Authority. (2009). Investigation of usage condition of gambling in South Korea. Seoul: Korea University.

Korean National Gaming Control Commission. (2009). A white paper on gambling industry. Seoul: Korean National Gaming Control Commission.

Korean National Gaming Control Commission. (2010). Investigation of usage condition of gambling industry in South Korea. Seoul: Korean National Gaming Control Commission.

Korean Problem Gambling Counseling Center. (2010). Prevalence of gambling addiction among OECD countries. Retrieved from http:// http://blog.naver.com/ goodcare8275/100115833234

Lee, H. P. (2002). Psychology of gambling. Seoul: Hakjisa Publications.

Lee, J. H. (2003). Validity analysis of Korean gambling industry (Unpublished doctoral dissertation), Hongik University, Seoul, South Korea.

Lee T. W. (2009). A study of the negative impacts of excessive gambling on casino patrons. Korean Criminological Review, 77, 1251-1284.

Lesieur, H. R., \& Rosenthal, R. J. (1991). Pathological gambling: A review of the literature 
(prepared for the American Psychiatric Association task force on DSM-IV committee on disorders of impulse control not elsewhere classified). Journal of Gambling Studies, 7, 5-39.

Leung, K. C., Wong, I. L. K., Lau, K. M., \& Yeung, S. C. (2010). Stress, health, and coping resources of Chinese pathological gamblers' spouses. Asian Journal of Gambling Issues and Public Health, 1, 61-74.

Park, C. H. (2008). A study on the soundness of gamble industry. Travel $\mathcal{E}$ Touring Study, 29, 21-48.

Park, J. H., Woo, J. M., Lee, S., \& Chung, I. J. (2007). Expansion plan of social services to support psychological and emotional health. Seoul: People's Institute of Economic \& Social Studies.

Pietrzak, R. H., \& Petry, N. M. (2006). Severity of gambling problems and psychosocial functioning in older adults. Journal of Geriatric Psychiatry Neurology, 19, 106-113.

Van Maanen, J. (1988). Tales of the field: on writing ethnography. Chicago, IL: University of Chicago Press. 